\title{
Analisis Perlakuan Risiko Medicarion Error Di Instalasi Farmasi Rumah Sakit Karitas
}

Didik Hadi Santosa, Grace Rumengan, dan Nurcahyo Andarusito

RS Karitas, Universitas Respati Indonesia

Email:didikhadisantosa17@gmail.com

\begin{abstract}
Abstrak
Medication error merupakan tantangan bagi Rumah Sakit dalam bidang keselamatan pasien karena berdampak merugikan bagi pasien. menganalisis medication error tahap prescribing, transcribing, dispensing dan administration di Instalasi Farmasi RS Karitas. Penelitian ini menggunakan deskriptif analisis dengan pendekatan kualitatif melalui wawancara mendalam, observasi dan telaah dokumen. Telaah dokumen resep pada bulan februari 2021. Hasil dari penelitian ini 400 resep yang teridentifikasi risiko medication error teridentifikasi risiko pada tahap prescribing yang terbanyak adalah tidak adanya paraf dokter (92\%), salah membaca nama obat (12\%) pada tahap transcribing, salah/tidak lengkap menulis etiket (80\%) pada tahap dispensing dan salah waktu pemberian obat (40\%) pada tahap administration. Penilaian risiko menunjukkan risiko yang teridentifikasi pada level/bands hijau dan biru. Tindak lanjut: investigasi sederhana dengan prosedur rutin. Perlakuan risiko yang dilakukan mengadakan komunikasi kepada petugas yang terlibat dalam berbagai tahapan pemberian obat. Kesimpulan adalah teridentifikasinya risiko medicarion error di instalasi farmasi RS Karitas yaitu tidak adanya paraf dokter pada tahap prescribing, salah membaca nama obat pada tahap transcribing, salah/tidak lengkap menulis etiket pada tahap dispensing, dan salah waktu pemberian obat pada tahap administration. Sebaiknya RS Karitas menggunakan sistem peresepan elektronik ( $e$ prescribing) dalam upaya menurunkan jumlah kasus medication error, pelatihan oleh unit diklat tentang kebijakan, SPO dan alur proses di instalasi farmasi bagi apoteker dan asisten apoteker baru untuk mempercepat adapatasi di instalasi farmasi RS Karitas.
\end{abstract}

Kata kunci : : Medication error, Perlakuan risiko,keselamatan pasien

\begin{abstract}
Medication error is a challenge for hospitals in the field of patient safety because it has a detrimental impact on patients. Purpose: to analyze medication errors in the prescribing, transcribing, dispensing and administration stages at the Karitas Hospital Pharmacy Installation. Descriptive analysis with a qualitative approach through in-depth interviews, observation and document review. Review of prescription documents in February 2021 Results: Of the 400 prescriptions identified risk of medication error, the most identified risk was the absence of doctor's initials (92\%), misreading of drug names (12\%) at the transcribing stage, incorrect / incomplete. wrote etiquette (80\%) at the dispensing stage and wrong timing of drug administration (40\%) at the administration stage. The risk assessment shows the identified risks on the green and blue levels / bands. Follow-up: simple investigations with routine procedures. Risk treatment is carried out by communicating with officers involved in various stages of drug administration. Conclusion was the identification of the risk of medicarion error in the pharmacy installation of Karitas Hospital, namely the absence of doctor's initials at the prescribing stage, misreading the name of the drug at the transcribing stage, incorrect / incomplete writing of the label at the dispensing stage, and incorrect timing of drug administration at the administration stage. It is better if Karitas Hospital uses an electronic prescribing system (e-prescribing) in an effort to reduce the number of cases of medication errors, training by the education and training unit on policies, SPO and process flow in pharmaceutical installations
\end{abstract}

Keywords: Medication error, risk treatment, patient safety 


\section{PENDAHULUAN}

Berdasarkan Peraturan Menteri Kesehatan Republik Indonesia nomor 4 tahun 2018 rumah sakit sebagai salah satu institusi pelayanan kesehatan mempunyai hak dan kewajiban. Kewajiban rumah sakit adalah memberi pelayanan kesehatan yang aman, bermutu, antidiskriminasi, dan efektif dengan mengutamakan kepentingan pasien sesuai dengan standar pelayanan Rumah Sakit (1). Untuk dapat memberikan kualitas pelayanan yang bermutu tinggi maka fasilitas pelayanan kesehatan harus memprioritaskan keselamatan pasien.(2). Pelayanan kesehatan yang tidak sesuai standar, termasuk pelayanan kefarmasian akan memiliki risiko timbulnya kesalahan dalam pengobatan (medication error) (3). Medication error memiliki dampak bagi pasien yang berobat ke rumah sakit baik rawat jalan maupun rawat inap, dapat berupa risiko ringan sampai yang paling berat dapat menyebabkan kematian.

Menurut buku pedoman pelaporan insiden keselamatan pasien dari Komite Keselamatan Pasien Rumah Sakit (KKPRS) dijelaskan bahwa Keselamatan Pasien / Patient Safety yaitu pasien bebas dari harm /cedera yang tidak seharusnya terjadi atau bebas dari harm yang potensial akan terjadi (penyakit, cedera fisik / sosial / psikologis, cacat, kematian dII), terkait dengan pelayanan kesehatan. Sehingga keselamatan pasien (patient safety) adalah proses dalam suatu Rumah Sakit yang memberikan pelayanan pasien yang lebih aman (4)). Sedangkan dalam Peraturan Menteri Kesehatan Republik Indonesia Nomor 1691 tahun 2011 tentang Keselamatan Pasien Rumah Sakit, keselamatan pasien (patient safety) adalah suatu sistem yang dilakukan oleh rumah sakit dalam rangka memberikan asuhan pasien lebih aman yang meliputi assesmen resiko, identifikasi dan pengelolaan hal yang berhubungan dengan resiko yang akan dialami oleh pasien, pelaporan dan analisa insiden, kemampuan belajar dari insiden dan tindak lanjutnya, implementasi solusi untuk meminimalkan timbulnya risiko dan mencegah cedera yang disebabkan karena kesalahan dalam pengambilan tindakan atau tidak melakukan tindakan yang seharusnya dilakukan (5). Pengertian patient safety menurut WHO yaitu : "the reduction of risk of unnecessary harm associated with health care to an acceptable minimum". Dapat diartikan bahwa patient safety adalah upaya untuk mengurangi risiko seminimal mungkin bahaya yang tidak perlu terkait perawatan kesehatan yang diterima (6)

Keselamatan Pasien RS (Hospital Patient Safety) dapat diartikan sebagai suatu sistem dimana rumah sakit membuat asuhan pasien lebih aman. Sistem tersebut meliputi assessmen risiko, identifikasi dan pengelolaan hal yang berhubungan dengan risiko pasien, pelaporan dan analisis insiden, kemampuan belajar dari insiden dan tindak lanjutnya serta implementasi solusi untuk meminimalkan timbulnya risiko. Sistem tersebut diharapkan dapat mencegah terjadinya cedera yang disebabkan oleh kesalahan akibat melaksanakan suatu tindakan atau tidak melakukan tindakan yang seharusnya dilakukan (4) Risiko adalah kemungkinan terjadinya suatu peristiwa yang berdampak negatif terhadap pencapaian sasaran organi

Proses Manajemen Risiko adalah suatu proses yang bersifat berkesinambungan, sistematis, logis, dan terukur yang digunakan untuk mengelola Risiko di instansi (7). Adibi, et al menyatakan bahwa elemen yang berpengaruh dalam pelaksanaan manajemen risiko yaitu prinsip dan komitmen organisasi; kepemimpinan dan pembimbingan; kewenangan, tanggung jawab dan komunikasi; perencanaan sistem dan tugas; sistem manajemen informasi dan monitoring (8).

Terdapat tujuh langkah dalam proses manajemen risiko, yaitu:

1. Menetapkan konteks.

2. Identifikasi.

3. Analisis.

4. Evaluasi.

5. Menangani risiko.

6. Pemantauan dan peninjauan berkelanjutan.

7. Komunikasi dan konsultasi (8)

Tahapan proses manajemen risiko terdiri atas:

a. komunikasi dan konsultasi;

b. penetapan konteks;

c. penilaian Risiko;

d. penanganan Risiko; dan

e. monitoring dan reviu. (7) 
Kesalahan pengobatan (Medication error) menurut "National Coordinating Council for Medication Error Reporting and Prevention (NCCMERP)" adalah setiap kejadian yang dapat dicegah yang dapat menyebabkan atau menyebabkan penggunaan obat yang tidak tepat atau membahayakan pasien saat pengobatan berada dalam kendali profesional perawatan kesehatan, pasien, atau konsumen. Peristiwa tersebut mungkin terkait dengan praktik profesional, produk perawatan kesehatan, prosedur, dan sistem, termasuk peresepan, komunikasi pesanan, pelabelan produk, pengemasan, dan tata nama, peracikan, pengeluaran, distribusi, administrasi, pendidikan, pemantauan, dan penggunaan (9). Dalam Keputusan Menteri Kesehatan RI Nomor 35 tahun 2014 tentang standard pelayanan kefarmasian di apotek, dikatakan bahwa medication error adalah kejadian yang dapat merugikan keselamatan pasien akibat pemakaian obat selama dalam pengawasan pengobatan tenaga kesehatan, yang sebetulnya dapat dicegah (10)

Medication error merupakan kejadian yang tidak berdiri sendiri, tetapi merupakan rangkaian kejadian dan melibatkan banyak faktor. Menurut WHO (2016), terdapat berbagai macam faktor yang mempengaruhi medication error, yaitu:

1. Faktor yang berkaitan dengan petugas kesehatan (SDM).

a) Kurangnya pelatihan tentang pengobatan.

b) Pengetahuan dan pengalaman tentang obat-obatan yang tidak memadai.

c) Minimnya pengetahuan tentang profil pasien.

d) Persepsi tentang resiko yang tidak memadai.

e) Kelebihan beban kerja atau kelelahan dari petugas kesehatan.

f) Masalah kesehatan fisik dan emosional.

g) Komunikasi yang buruk antara petugas kesehatan dengan pasien.

2. Faktor yang berkaitan dengan pasien a) Karakteristik pasien (misal., kepribadian, kemampuan aksara dan masalah bahasa).

b) Kompleksitas kasus klinis, termasuk kondisi kesehatan pasien, polifarmasi dan pengobatan beresiko tinggi.

3. Faktor yang berkaitan dengan lingkungan kerja

a) Tekanan pekerjaan dan waktu.

b) Gangguan yang berasal dari staff lain dan pasien.

c) Lemahnya protokol dan prosedur yang terstandarisasi

d) Sumber daya yang tidak mencukupi.

e) Masalah yang berhubungan dengan lingkungan kerja secara fisik (misal., pencahayaan, temperature dan ventilasi).

4. Faktor yang berkaitan dengan obat-obatan

a) Penamaan obat-obatan.

b) Pelabelan dan pengemasan.

5. Faktor yang berkaitan dengan tugas

a) Sistem yang berulang untuk pemesanan, pemrosesan dan ototrisasi.

b) Pemantauan pasien (bergantung pada pengalaman, pasien, pengaturan perawatan kesehatan yang lain, prescriber).

6. Faktor yang berkaitan dengan komputerisasi sistem informasi

a) Kesulitan dalam memproses resep pertama (misal., daftar pilihan obat, regimen dosis standard dan peringatan yang terlewat)

b) Kesulitan dalam memproses untuk menghasilkan pengulangan resep yang benar.

c) Kurangnya akurasi catatan pasien.

d) Desain yang tidak memadai yang memungkinkan kesalahan yang dilakukan oleh petugas (human error).

7. Penghubung antara pelayanan kesehatan primer dan sekunder

a) Terbatasnya komunikasi dengan tenaga medis ditingkat sekunder. 
b) Kurangnya justifikasi rekomendasi dari pelayanan kesehatan tingkat sekunder.(9)

Jumlah kasus insiden keselamatan pasien yang dilaporkan oleh RS di Indonesia adalah sebanyak 289 kasus di tahun 2015, 668 kasus di tahun 2016, 1647 kasus di tahun 2017, 1489 kasus di tahun 2018 dan 7465 kasus di tahun 2019. Sedangkan berdasarkan jenis insiden di tahun 2019 yaitu KNC sebanyak 38\%, KTD dan KTC masing-masing sebanyak 31\%. Jumlah kasus berdasarkan akibat insiden menurut data kementerian kesehatan terdiri dari kematian sebanyak 171 kasus, cedera berat 80 kasus, cedera sedang 372 kasus, cedera ringan 1183 kasus dan tidak ada cedera 5659 kasus. (12).

Berdasarkan rekapan data Insiden Keselamatan Pasien (IKP) dari Komite Peningkatan Mutu dan Keselamatan Pasien (PMKP) RS Karitas tahun 2018 didapatkan 2 kasus IKP yaitu 1 kasus insiden Kejadian Tidak Cidera (KTC), 1 kasus insiden Kejadian Nyaris Cedera (KNC). Persentase kasus medication error yang terjadi pada bulan September - November 2020 di poliklinik dokter spesialis RS Karitas terdiri dari 10,5\% kasus pasien anak, 52,6\% kasus pasien penyakit dalam, $5,2 \%$, kasus pasien bedah dan $31,6 \%$ kasus pasien obstetri ginekologi. Dari data persentase kasus diatas dapat disimpulkan bahwa kasus medication error di poliklinik RS Karitas dengan urutan dari kasus yang terbanyak meliputi klinik penyakit dalam, klinik obstetric ginekologi, klinik anak dan klinik bedah.

Medication error masih sering terjadi di berbagai institusi termasuk dalam pelayanan kesehatan. Medication error memiliki dampak bagi pasien yang berobat ke rumah sakit baik rawat jalan maupun rawat inap, dapat berupa risiko ringan sampai yang paling berat dapat menyebabkan kematian

Instalasi Farmasi merupakan unit di rumah sakit yang mempunyai tanggungjawab di dalam pelayanan obat dan bahan habis pakai. Banyaknya jumlah resep yang dilayani oleh instalasi farmasi mempunyai risiko terjadinya kesalahan dalam pelayanan obat-obatan. Jumlah kasus medication error yang terjadi di rumah sakit harus dikurangi untuk dapat mencapai tujuan pasien safety.

http://ejournal.urindo.ac.id/index.php/MARSI
Tujuan penelitian ini adalah menganalisis medication error pada tahap Prescribing, Transcribing, Dispensing dan Administration di Instalasi Farmasi Rumah Sakit Karitas. Manfaat dari penelitian ini bagi Rumah Sakit Sebagai informasi data untuk perbaikan dalam penanganan kasus medication error di Instalasi Farmasi Rumah Sakit Karitas, bagi publikasi sebagai informasi bagi masyarakat mengenai manajemen risiko kefarmasian rumah sakit.

\section{METODE}

Penelitian ini menggunakan metode analisis deskriptif dengan pendekatan kualitatf dengan cara melakukan observasi, wawancara dan telaah dokumen. Jumlah populasi resep sebanyak 400 resep pasien rawat inap yang masuk di instalasi farmasi RS Karitas pada bulan februari 2021. Jumlah sample dalam penelitian ini sama dengan populasi. Wawancara dilakukan kepada para informan yang terdiri dari dokter spesialis penyakit dalam, dokter spesialis obstetric, dokter spesialis anak, apoteker, asisten apoteker dan perawat di ruang rawat inap SMF penyakit dalam,SMF obstetric ginekologi dan SMF Anak.

\section{HASIL}

Dalam penelitian ini peneliti akan melakukan analisis tentang input, proses dan output pemberian obat di RS Karitas. Input terdiri dari Sumber Daya Manusia (SDM), Kebijakan, SPO dan alur proses; resep. Proses melihat tahapan pemberian obat yang terdiri dari tahap prescribing, tahap transcribing, tahap dispensing dan tahap administration. Sedangkan dalam output akan dilakukan identifikasi, analisis dan perlakuan resiko.

Informan dalam penelitian ini terdiri dari direktur, dokter spesialis penyakit dalam satu orang, dokter spesialis obstetri ginekologi satu orang, dokter spesialis anak satu orang, apoteker satu orang, asisten apoteker empat orang dan kepala komite PMKP satu orang. Pada awal bulan februari 2021 di instalasi farmasi RS Karitas ada penambahan jumlah apoteker sebanyak tiga orang dan asisten apoteker sebanyak satu orang. Namun dalam penelitian ini apoteker dan asisten apoteker yang baru tersebut tidak masuk dalam kriteria 
informan penelitian ini. Karakteristik informan berdasarkan usia, pendidikan, masa kerja dan status karyawan dapat dilihat pada table 1

Tabel 1. Karakteristik Informan

\begin{tabular}{|c|c|c|c|c|c|c|}
\hline No & $\begin{array}{c}\text { Informa } \\
n\end{array}$ & Usia & Pendidikan & $\begin{array}{l}\text { Masa } \\
\text { Kerja }\end{array}$ & $\begin{array}{c}\text { Status } \\
\text { Karyawa } \\
\mathrm{n}\end{array}$ & $\begin{array}{c}\text { Kod } \\
\text { e }\end{array}$ \\
\hline 1. & $\begin{array}{l}\text { Perawat } \\
\text { Ruang } \\
\text { Maria } 1\end{array}$ & $\begin{array}{l}36 \\
\text { tahu } \\
n\end{array}$ & $\begin{array}{l}\text { D3- } \\
\text { Keperawata } \\
\text { n }\end{array}$ & $\begin{array}{c}>3 \\
\text { tahu } \\
n\end{array}$ & $\begin{array}{l}\text { Karyawa } \\
\text { n tetap }\end{array}$ & $\mathrm{X} 1$ \\
\hline 2. & $\begin{array}{l}\text { Perawat } \\
\text { Ruang } \\
\text { Maria } 2\end{array}$ & $\begin{array}{l}28 \\
\text { tahu } \\
n\end{array}$ & $\begin{array}{l}\text { D3- } \\
\text { Keperawata } \\
\text { n }\end{array}$ & $\begin{array}{c}>3 \\
\text { tahu } \\
n\end{array}$ & $\begin{array}{l}\text { Karyawa } \\
\text { n kontrak }\end{array}$ & $\times 2$ \\
\hline 3. & $\begin{array}{l}\text { Perawat } \\
\text { Ruang } \\
\text { Elisabeth } \\
1\end{array}$ & $\begin{array}{l}31 \\
\text { tahu } \\
n\end{array}$ & $\begin{array}{l}\text { D3- } \\
\text { Kebidanan }\end{array}$ & $\begin{array}{c}>3 \\
\text { tahu } \\
\mathrm{n}\end{array}$ & $\begin{array}{l}\text { Karyawa } \\
\text { n tetap }\end{array}$ & x3 \\
\hline 4. & $\begin{array}{l}\text { Perawat } \\
\text { Ruang } \\
\text { Elisabeth } \\
2\end{array}$ & $\begin{array}{l}29 \\
\text { tahu } \\
n\end{array}$ & $\begin{array}{l}\text { D3- } \\
\text { Kebidanan }\end{array}$ & $\begin{array}{l}>3 \\
\text { tahu } \\
\mathrm{n}\end{array}$ & $\begin{array}{l}\text { Karyawa } \\
\text { n tetap }\end{array}$ & X4 \\
\hline 5. & $\begin{array}{l}\text { Perawat } \\
\text { Ruang } \\
\text { Emanuel } \\
1\end{array}$ & $\begin{array}{l}27 \\
\text { tahu } \\
n\end{array}$ & $\begin{array}{l}\text { S1- } \\
\text { Keperawata } \\
\mathrm{n}\end{array}$ & $\begin{array}{l}>3 \\
\text { tahu } \\
\mathrm{n}\end{array}$ & $\begin{array}{l}\text { Karyawa } \\
\text { n tetap }\end{array}$ & X5 \\
\hline 6. & $\begin{array}{l}\text { Perawat } \\
\text { Ruang } \\
\text { Emanuel } \\
2\end{array}$ & $\begin{array}{l}26 \\
\text { tahu } \\
n\end{array}$ & $\begin{array}{l}\text { D3- } \\
\text { Keperawata } \\
n\end{array}$ & $\begin{array}{l}>3 \\
\text { tahu } \\
\mathrm{n}\end{array}$ & $\begin{array}{l}\text { Karyawa } \\
\text { n tetap }\end{array}$ & x6 \\
\hline 7. & $\begin{array}{l}\text { Dokter } \\
\text { Sp.PD }\end{array}$ & $\begin{array}{l}51 \\
\text { tahu } \\
n\end{array}$ & $\begin{array}{l}\text { S3-Dokter } \\
\text { Spesialis }\end{array}$ & $\begin{array}{l}>3 \\
\text { tahu } \\
\mathrm{n}\end{array}$ & $\begin{array}{l}\text { Karyawa } \\
\text { n kontrak }\end{array}$ & $x 7$ \\
\hline 8. & $\begin{array}{l}\text { Dokter } \\
\text { Sp.OG }\end{array}$ & $\begin{array}{l}33 \\
\text { tahu } \\
n\end{array}$ & $\begin{array}{l}\text { S1-Dokter } \\
\text { Spesialis }\end{array}$ & $\begin{array}{l}>3 \\
\text { tahu } \\
\mathrm{n}\end{array}$ & $\begin{array}{l}\text { Karyawa } \\
\text { n kontrak }\end{array}$ & $x 8$ \\
\hline 9. & $\begin{array}{l}\text { Dokter } \\
\text { Sp.A }\end{array}$ & $\begin{array}{l}35 \\
\text { tahu } \\
n\end{array}$ & $\begin{array}{l}\text { S1-Dokter } \\
\text { Spesialis }\end{array}$ & $\begin{array}{l}>3 \\
\text { tahu } \\
\mathrm{n}\end{array}$ & $\begin{array}{l}\text { Karyawa } \\
\text { n kontrak }\end{array}$ & X9 \\
\hline 10. & $\begin{array}{l}\text { Apoteke } \\
r\end{array}$ & $\begin{array}{l}34 \\
\text { tahu } \\
n\end{array}$ & S1-Apoteker & $\begin{array}{l}>3 \\
\text { tahu } \\
\mathrm{n}\end{array}$ & $\begin{array}{l}\text { Karyawa } \\
\text { n kontrak }\end{array}$ & $\mathrm{X} 10$ \\
\hline 11. & $\begin{array}{l}\text { Asisten } \\
\text { Apoteke } \\
\text { r } 1\end{array}$ & $\begin{array}{l}31 \\
\text { tahu } \\
\mathrm{n}\end{array}$ & $\begin{array}{l}\text { D3- } \\
\text { Administrasi } \\
\text { farmasi }\end{array}$ & $\begin{array}{l}>3 \\
\text { tahu } \\
\mathrm{n}\end{array}$ & $\begin{array}{l}\text { Karyawa } \\
\text { n tetap }\end{array}$ & X11 \\
\hline 12. & $\begin{array}{l}\text { Asisten } \\
\text { Apoteke } \\
\text { r } 2\end{array}$ & $\begin{array}{l}37 \\
\text { tahu } \\
n\end{array}$ & D1-farmasi & $\begin{array}{l}>3 \\
\text { tahu } \\
\mathrm{n}\end{array}$ & $\begin{array}{l}\text { Karyawa } \\
\text { n tetap }\end{array}$ & $\mathrm{X} 12$ \\
\hline 13. & $\begin{array}{l}\text { Asisten } \\
\text { Apoteke } \\
\text { r } 3\end{array}$ & $\begin{array}{l}38 \\
\text { tahu } \\
n\end{array}$ & D1-farmasi & $\begin{array}{l}>3 \\
\text { tahu } \\
\mathrm{n}\end{array}$ & $\begin{array}{l}\text { Karyawa } \\
\text { n tetap }\end{array}$ & $\mathrm{X} 13$ \\
\hline
\end{tabular}

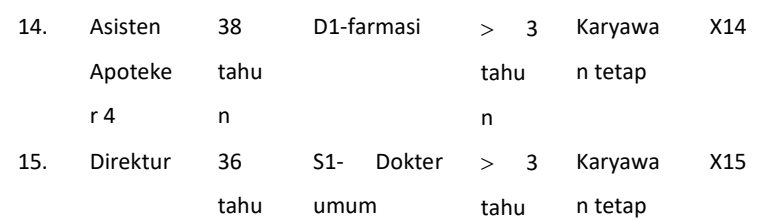

Berdasarkan tabel 1. dapat diketahui karakteristik informan terdiri atas :

1. Usia informan berkisar antara 26 tahun -51 tahun.

2. Pendidikan dari informan terdiri atas S3 Dokter Spesialis, S1 Dokter Spesialis, S1 Dokter Umum, S1 Apoteker, D3 Administrasi Farmasi, D1 farmasi, S1 Keperawatan, D3 keperawatan dan D3 Kebidanan.

3. Masa kerja dari informan keseluruhan diatas 3 tahun

4. Status karyawan informan terdiri atas 5 orang karyawan kontrak dan 10 orang karyawan tetap.

Dari hasil observasi dan wawancara yang dilakukan kepada informan dapat diketahui bahwa pengetahuan para informan tentang medicarion error sudah cukup baik. Kebijakan, SPO dan alur proses kefarmasian sudah ada, mudah dibaca dan dipahami oleh petugas farmasi, namun dalam pelaksanaannya kadangkala ada beberapa prosedur yang terlewati oleh petugas disebabkan jumlah resep yang masuk ke instalasi farmasi meningkat.

Dalam penelitian ini dilakukan telaah resep pasien rawat inap yang masuk pada bulan Februari 2021. Jumlah resep yang masuk sebanyak 400 resep yang merupakan jumlah populasi dalam penelitian ini. Dari hasil telaah resep didapatkan sebanyak 400 resep teridentifikasi dapat menyebabkan risiko terjadinya medication error jumlah sample pada penelitian ini sama dengan jumlah populasi yakni semua resep pasien rawat inap pada bulan Februari 2021. Dalam telaah resep dilakukan pemeriksaan kelengkapan penulisan resep. Dari hasil telaah resep terhadap 400 resep, didapatkan kesalahan yang terindikasi berisiko menyebabkan medication error pada tahap Prescribing seperti terlibat pada table 


\section{Tabel 2. Identifikasi Kesalahan Pada Tahap Prescribing Yang Berisiko Menyebabkan Medication Error}

\begin{tabular}{|c|c|c|c|}
\hline No & Jenis Kesalahan & Jumlah & Persentase \\
\hline 1 & Tidak ada paraf dokter & 368 & $92 \%$ \\
\hline 2 & Tidak ada alamat pasien & 320 & $80 \%$ \\
\hline 3 & Tidak ada nomor SIP & 280 & $70 \%$ \\
\hline 4 & $\begin{array}{l}\text { Tidak ada berat badan, } \\
\text { tinggi badan pasien }\end{array}$ & 280 & $70 \%$ \\
\hline 5 & Aturan pakai tidak ada & 240 & $60 \%$ \\
\hline 6 & $\begin{array}{l}\text { Tidak ada nama } \\
\text { ruangan/unit pengirim }\end{array}$ & 240 & $60 \%$ \\
\hline 7 & $\begin{array}{l}\text { Tidak menuliskan rute } \\
\text { pemberian obat }\end{array}$ & 200 & $50 \%$ \\
\hline 8 & $\begin{array}{l}\text { Tidak ada bentuk dan } \\
\text { kekuatan obat }\end{array}$ & 172 & $43 \%$ \\
\hline 9 & $\begin{array}{l}\text { Tidak ada jenis kelamin } \\
\text { pasien }\end{array}$ & 104 & $26 \%$ \\
\hline 10 & Tidak ada umur pasien & 52 & $13 \%$ \\
\hline 11 & $\begin{array}{l}\text { Tulisan resep tidak } \\
\text { terbaca dengan jelas }\end{array}$ & 48 & $12 \%$ \\
\hline 12 & $\begin{array}{l}\text { Penulisan nama obat } \\
\text { dengan singkatan yang } \\
\text { tidak lazim }\end{array}$ & 20 & $5 \%$ \\
\hline
\end{tabular}

Dari hasil di atas dapat terlihat bahwa kesalahan yang teridentifikasi berisiko menyebabkan medication error pada tahap Prescribing yang paling sering adalah tidak ada paraf dokter yaitu sebanyak 368 kasus (92\%), kemudian berturutturut dari jumlah terbanyak yang teridentifikasi adalah tidak ada alamat pasien sebanyak 320 kasus (80\%), tidak ada nomor SIP sebanyak 280 kasus (70\%), tidak ada berat badan/tinggi badan pasien sebanyak 280 kasus (70\%), tidak ada aturan pakai sebanyak 240 kasus (60\%), tidak ada nama ruangan/unit pengirim sebanyak 240 kasus (60\%), tidak menuliskan rute pemberian obat sebanyak 200 kasus (50\%), tidak ada bentuk dan kekuatan obat sebanyak 172 kasus (43\%), tidak ada jenis kelamin pasien sebanyak 104 kasus (26\%), tidak ada umur pasien sebanyak 52 kasus (13\%), tulisan resep tidak terbaca dengan jelas sebanyak 48 kasus (12\%), dan penulisan nama obat dengan singkatan yang tidak lazim sebanyak 20 kasus (5\%).

Penulisan resep yang jelas dan lengkap memegang peranan penting dalam pencegahan medication error. Berdasarkan Peraturan Menteri Kesehatan Republik Indonesia nomor 72 tahun 2016 tentang Standar Kefarmasian Rumah Sakit menjelaskan tentang kelengkapan penulisan resep yang harus memenuhi persyaratan administrasi, persyaratan farmasetik dan persyaratan klinis. Resep yang disertai dengan paraf dokter diperlukan supaya resep menjadi otentik dan tidak disalahgunakan terutama untuk obat narkotika dan psikotropika. Tidak adanya paraf dokter pada sebagian besar resep pasien rawat inap di RS Karitas pada bulan februari 2021 menunjukkan bahwa belum adanya persamaan persepsi para dokter tentang pentingnya pencantuman paraf dokter. Penulisan alamat pasien sangat diperlukan agar jika timbul kesalahan pengobatan, petugas dapat menghubungi pasien dengan segera. Banyaknya aktivitas yang dilakukan oleh dokter spesialis di RS Karitas yakni visit pasien, periksa pasien poli maupun menerima konsul dari dokter lain menyebabkan ketidaklengkapan pencatatan identitas pasien termasuk alamat pasien. Pemecahan masalah yang dapat dilakukan yaitu dengan cara meminta petugas administrasi atau perawat pasien rawat inap untuk membantu mengisi kelengkapan identitas pasien termasuk alamat pasien. Pencantuman nomor SIP dokter merupakan bukti bahwa dokter yang melaksanakan praktek memiliki aspek legalitas. Pembuatan cap nama dokter disertai nomor SIP dokter tersebut merupakan solusi dari permasalahan tersebut. Penulisan berat badan pasien diperlukan dalam perhitungan dosis obat yang diberikan oleh dokter. Solusi dari permasalahan ini adalah dengan meminta bantuan perawat untuk menimbang seluruh pasien yang akan diperiksa dan menuliskan hasil pengukuran berat badan pasien tersebut di lembar resep. Dalam sebuah resep penulisan aturan pakai merupakan sesuatu hal yang penting agar obat tersebut tepat penggunaan. Tidak adanya aturan pakai akan menimbulkan kebingungan dari pasien sehingga dapat menimbulkan kesalahan dalam pemakaian obat. Apoteker dapat mengingatkan para dokter jika sebuah resep belum dilengkapi oleh aturan pakai agar pasien menjadi jelas tentang pemakaian obat yang diberikan. Penulisan nama ruangan/unit pengirim akan memperjelas bagi petugas farmasi dalam mengirimkan obat yang telas dilakukan dispensing. Petugas farmasi harus mengingatkan petugas di unit rawat jalan maupun rawat inap untuk mengisi nama ruangan/unit pengirim jika resep tersebut belum 
ada nama ruangan/unit pengirimnya. Penulisan rute pemberian obat akan memperjelas bagi perawat yang akan memberikan obat kepada pasien. Jika sebuah resep belum ada rute pemberian obat maka petugas farmasi harus menanyakan kepada dokter penulis resep agar menambahkan rute pemberian obat dalam resep tersebut. Informasi tentang bentuk dan kekuatan obat sangat bermanfaat bagi petugas farmasi dalam menyiapkan obat dengan benar. Maka petugas farmasi harus menghubungi dokter pembuat resep agar mengisi bentuk dan kekuatan obat jika dalam resep tersebut belum ada. Informasi tentang umur dan jenis kelamin pasien adalah hal yang penting agar tidak menimbulkan kesalahan pemberian obat pada orang yang salah. Penulisan identitas tersebut dapat dibantu oleh petugas administrasi atau perawat agar identitas umur dan jenis kelamin menjadi lengkap dalam resep. Penulisan resep yang dapat terbaca jelas merupakan hal yang penting agar apoteker tidak salah dalam membaca resep tersebut. Petugas farmasi dapat menghubungi dokter pembuat resep jika timbul keraguan tentang tulisan resep yang tidak jelas. Komite Medis juga perlu untuk melakukan pembinaan para dokter agar penulisan resep menjadi jelas dan dapat dibaca dengan baik. Singkatan-singkatan yang tidak lazim yang digunakan dalam resep dapat menimbulkan kesalahan dalam menerjemahkan obat yang ditulis dalam resep tersebut. Rumah sakit Karitas harus menetapkan singkatan-singkatan yang lazim digunakan dalam penulisan resep.

Hasil telaah resep dan telaah salinan resep di instalasi farmasi RS Karitas pada bulan Februari 2021, didapatkan hasil kesalahan yang teridentifikasi berisiko menyebabkan medication error pada tahap transcribing adalah sebagai berikut :
Tabel 3. Identifikasi Kesalahan Pada Tahap Transcribing Yang Berisiko Menyebabkan Medication Error

\begin{tabular}{clcc}
\hline No & \multicolumn{1}{c}{ Jenis Kesalahan } & Jumlah & Persentase \\
\hline 1. & $\begin{array}{l}\text { Salah membaca nama } \\
\text { pasien }\end{array}$ & 0 & $0 \%$ \\
2. & $\begin{array}{l}\text { Salah membaca nama } \\
\text { obat }\end{array}$ & 48 & $12 \%$ \\
3. & $\begin{array}{l}\text { Salah membaca dosis } \\
\text { obat }\end{array}$ & 0 & $0 \%$ \\
4. & $\begin{array}{l}\text { Salah membaca aturan } \\
\text { pakai }\end{array}$ & 40 & $10 \%$ \\
5. & $\begin{array}{l}\text { Salah membaca rute } \\
\text { pemberian }\end{array}$ & 20 & $5 \%$ \\
6. & $\begin{array}{l}\text { Salah membaca durasi } \\
\text { pemberian obat }\end{array}$ & 0 & $0 \%$ \\
7. Salah membaca bentuk \\
sediaan obat
\end{tabular}

Dari 7 poin kesalahan yang dapat terjadi pada tahap transcribing, di RS Karitas hanya ditemukan 4 poin kesalahan yaitu salah membaca nama obat, salah membaca aturan pakai, salah membaca rute pemberian dan salah membaca bentuk sediaan obat. Salah membaca nama obat merupakan kesalahan yang terbanyak terjadi di RS Karitas pada tahap transcribing. Berdasarkan hasil wawancara terhadap informan dapat diketahui bahwa kesalahan ini disebabkan tulisan dokter yang susah dibaca, petugas farmasi tidak menguasai nama obat yang ada di apotek, kurang teliti membaca resep dan beban kerja yang meningkat. Kesalahan membaca aturan pakai merupakan kesalahan kedua terbanyak yang terjadi di RS Karitas. Banyaknya resep yang tidak mencantumkan aturan pakai pada tahap prescribing adalah penyebab kesalahan membaca aturan pakai pada tahap transcribing. Hal yang sama terjadi pada kesalahan membaca rute pemberian obat dan salah membaca bentuk sediaan obat. Penyebabnya adalah ketidaklengkapan penulisan resep pada tahap transcribing dan penulisan resep yang susah dibaca.

Dari hasil telaah resep, didapatkan bentuk kesalahan yang teridentifikasi berisiko menyebabkan medication error sebagai berikut pada tahap Dispensing sebagai berikut : 
Tabel 4. Identifikasi Kesalahan Pada Tahap Dispensing Yang Berisiko Menyebabkan Medication Error

\begin{tabular}{|c|c|c|c|}
\hline No & Jenis Kesalahan & Jumlah & Persentase \\
\hline 1 & Salah pengambilan obat & 10 & $2,5 \%$ \\
\hline 2 & $\begin{array}{ll}\text { Salah/tidak } & \text { lengkap } \\
\text { menulis etiket } & \end{array}$ & 320 & $80 \%$ \\
\hline 3 & Salah menghitung dosis & 8 & $2 \%$ \\
\hline 4 & $\begin{array}{l}\text { Salah memberikan } \\
\text { jumlah obat }\end{array}$ & 5 & $1,25 \%$ \\
\hline 5 & $\begin{array}{l}\text { Salah mencantumkan } \\
\text { identitas pasien }\end{array}$ & 40 & $10 \%$ \\
\hline 6 & $\begin{array}{ll}\text { Tidak } & \text { memberikan } \\
\text { informasi } & \text { yang jelas } \\
\text { tentang } & \text { penggunaan } \\
\text { obat kepada pelanggan }\end{array}$ & 240 & $60 \%$ \\
\hline
\end{tabular}

Pada tahap dispensing terdapat 6 poin kesalahan pemberian obat yaitu salah pengambilan obat, salah/tidak lengkap menulis etiket, salah menghitung dosis, salah memberikan jumlah obat, salah mencantumkan identitas pasien dan tidak memberikan informasi yang jelas tentang penggunaan obat kepada pelanggan. Berdasarkan wawancara dan observasi terhadap informan, kesalahan pengambilan obat diakibatkan oleh nama obat yang mirip (LASA). Pelabelan obat-obat LASA perlu dilakukan sebagai upaya dalam mencegah timbulnya kesalahan pengambilan obat. Salah/tidak lengkap menulis etiket merupakan kesalahan yang terbanyak terjadi pada tahap dispensing di RS Karitas. Berdasarkan hasil wawancara dan observasi, kesalahan ini terjadi akibat ketidaktelitian dan kelalaian petugas dalam penulisan etiket. Kesalahan menghitung dosis disebabkan oleh kesalahan pada tahap sebelumnya yaitu tahap transcribing dan tahap prescribing. Ketidaktelitian petugas dan tidak dilakukannya crosscheck merupakan penyebab kesalahan memberikan jumlah obat dan salah mencantumkan identitas pasien. Kesalahan tidak memberikan informasi yang jelas tentang penggunaan obat merupakan kesalahan kedua terbanyak yang terjadi pada tahap dispensing di RS Karitas. Berdasarkan hasil observasi pemberian informasi obat sebagian besar diberikan oleh apoteker, banyaknya jumlah resep kadangkala menjadi penyebab kelalaian petugas dalam memberikan informasi yang jelas tentang penggunaan obat kepada pasien.

Dari hasil telaah laporan kejadian di Unit Farmasi Rawat Inap dan observasi langsung di
Instalasi Rawat Inap, didapatkan hasil sebagai berikut :

Tabel 5. Identifikasi Kesalahan Pada Tahap Administration Yang Berisiko Menyebabkan Medication Error

\begin{tabular}{|c|c|c|c|}
\hline No & Jenis Kesalahan & Jumlah & Persentase \\
\hline 1. & Salah pemberian obat & 2 & $0,46 \%$ \\
\hline 2. & $\begin{array}{l}\text { Salah waktu pemberian } \\
\text { obat }\end{array}$ & 160 & $40 \%$ \\
\hline 3. & $\begin{array}{l}\text { Salah teknik pemberian } \\
\text { obat }\end{array}$ & 40 & $10 \%$ \\
\hline 4. & $\begin{array}{lr}\text { Tidak } & \text { memberikan } \\
\text { informasi yang jelas } & \text { yan obat } \\
\text { tentang penggunaan obluarga } \\
\text { kepada pasien/keluara } \\
\text { pasien }\end{array}$ & 80 & $20 \%$ \\
\hline
\end{tabular}

Berdasarkan observasi yang dilakukan di instalasi rawat inap RS Karitas baik di ruang Maria (SMF Penyakit Dalam), ruang Elisabeth (SMF Obstetri Ginekologi) dan ruang Emanuel (SMF Anak) ditemukan kesalahan pemberian obat sebanyak 2 kasus (0,46\%). Kesalahan ini disebabkan oleh tidak adanya gelang pasien saat petugas memberikan obat kepada pasien. Kesalahan terbanyak yang terjadi pada tahap administration adalah salah waktu pemberian obat, sebanyak 160 kasus (40\%). Berdasarkan observasi dan wawancara kepada perawat di instalasi rawat inap dapat diketahui bahwa penyebab kesalahan ini adalah waktu penyiapan obat yang lama dari petugas di instalasi farmasi. Kondisi saat ini di RS Karitas obat tidak diantarkan oleh petugas farmasi namun perawat yang mengambil obat ke instalasi farmasi. Kesalahan yang berikutnya adalah salah teknik pemberian obat, yaitu sebanyak 40 kasus (10\%). Kesalahan teknik pemberian obat ini disebabkan tidak lengkapnya etiket pemberian obat dari farmasi. Kesalahan yang terakhir pada tahap administration adalah tidak memberikan informasi yang jelas tentang penggunaan obat kepada pasien/keluarga pasien. Dari hasil observasi dapat diketahui bahwa saat memberikan obat kepada pasien, terdapat perbedaan tindakan perawat tentang pemberian informasi penggunaan obat. Sebagian perawat memberikan penjelasan secara lengkap dan jelas, sebagian perawat lainnya memberikan penjelasan singkat tentang penggunaan obat, sebagian lagi tidak disertai pemberian informasi penggunaan obat. Diperlukan keseragaman tindakan perawat dalam 
pemberian informasi penggunaan obat kepada pasien/keluarga di RS Karitas agar dapat mengurangi kasus medication error.

Menurut Swiss Cheese Theory lubanglubang dalam lapisan keju adalah hambatanhambatan yang ditemukan dalam pelayanan di RS. banyaknya hambatan di instalasi farmasi dan instalasi rawat inap dalam proses pemberian obat kepada pasien merupakan sesuatu hal yang harus diambil tindakan oleh pimpinan RS Karitas. Hambatan ditemukan dalam tahap prescribing yaitu sebagian besar resep tidak ada paraf dokter, hambatan pada tahap transcribing yang terbanyak yaitu salah membaca nama obat, hambatan pada tahap dispensing yaitu salah/tidak lengkap dalam menulis etiket dan hambatan pada tahap administration yaitu salah waktu pemberian obat.

\section{KESIMPULAN}

1. Pengetahuan dokter, petugas farmasi dan perawat tentang medication error dalam pelayanan masing-masing baik tahap Prescribing, Transcribing, Dispensing dan Administration sudah cukup baik..

2. Kebijakan, Standar Prosedur Operasional dan Alur Proses sudah ada dan mudah dibaca, dipahami oleh petugas. Namun dalam pelaksanaannya masih belum konsisten.

3. Dari semua resep yang masuk pada bulan Februari 2021 terdapat 400 resep yang teridentifikasi berisiko menyebabkan medication error melalui pemeriksaan kelengkapan resep. Teridentifikasinya risiko medication error dengan jumlah kasus yang terbanyak pada tahap Prescribing yaitu tidak ada paraf dokter sebanyak 368 kasus (92\%), tahap Transcribing yaitu salah membaca nama obat sebanyak 48 kasus (12\%), tahap Dispensing yaitu Salah/tidak lengkap menulis etiket sebanyak 320 kasus (80\%), dan tahap Administration yaitu salah waktu pemberian obat sebanyak 160 kasus (40\%).

4. Dari hasil penghitungan skor risiko yang dilakukan menggunakan Matriks Grading Risiko menunjukkan hasil level/ bands risiko berwarna biru dan hijau. Kontrol risiko yang perlu dilakukan supaya tidak ditemukan kesalahan pemberian obat lagi adalah dengan melakukan investigasi sederhana melalui prosedur rutin.

5. Perlakuan risiko yang dilakukan yaitu mengadakan komunikasi kepada petugas yang terlibat dalam berbagai tahapan pemberian obat yaitu para dokter penanggungjawab pelayanan (DPJP), apoteker yang melaksanakan proses skrining resep, asisten apoteker yang melaksanakan peracikan dan pengemasan obat, dan para perawat yang memberikan obat.

\section{Saran}

1. RS Karitas menggunakan sistem peresepan elektronik (e-prescribing) dalam upaya menurunkan jumlah kasus medication error di RS Karitas. Sistem ini sangat berguna bagi para dokter untuk mengurangi medication error tahap prescribing dan bagi petugas farmasi untuk mengurangi medication error tahap transcribing dan dispensing. Jika $e$ prescribing sudah berjalan baik sebaiknya RS Karitas menggunakan Automatic Tablet Dispensing \& Packaging System (ATDPS) bagi petugas farmasi untuk efisiensi waktu dispensing dan menurunkan risiko medication error pada tahap dispensing.

2. Sosialisasi oleh unit Diklat tentang uraian tugas, wewenang, kebijakan, SPO dan alur proses yang ada di instalasi farmasi oleh unit diklat bagi apoteker dan asisten apoteker.

3. RS Karitas menggunakan sistem Electronic Medication Management (EMM) jika $e$ prescribing dan sistem dispensing obat sudah berjalan baik maka dapat ditingkatkan dengan mengintegrasikan dalam sistem informasi rumah sakit (SIMRS).

4. Pelatihan yang diselenggarakan oleh unit diklat tentang komunikasi bagi dokter, perawat dan petugas farmasi dalam rangka meningkatkan komunikasi antara petugas pemberi pelayanan dengan pasien dan diantara petugas sendiri.

5. Pelatihan tentang kebijakan, pedoman, panduan, SPO dan alur proses yang ada di instalasi farmasi oleh unit diklat kepada apoteker dan asisten apoteker yang baru sehingga dapat mempercepat adapatasi di instalasi farmasi RS Karitas. 
Jurnal Manajemen Dan Administrasi Rumah Sakit Indonesia

Vol. 5 No 1, April 2021

\section{DAFTAR PUSTAKA}

1. Permenkes No. 4. Kewajiban Rumah Sakit dan Kewajiban Pasien. 2018;1-35.

2. Muiño Míguez $A$, Jiménez Muñoz $A B$, Pinilla Llorente $B$, Durán García ME, Cabrera Aguilar FJ, Rodríguez Pérez MP. Patient safety. An Med Interna. 2007;24(12):602-6.

3. Permenkes No. 72. Peraturan Menteri Kesehatan RI No. 72. 2016;

4. Komite Keselamatan Pasien Rumah Sakit. Pedoman Pelaporan Insiden Keselamatan Pasien (IKP). Kementrian Kesehat Republik Indones. 2015;25.

5. Permenkes. Keselamatan Pasien Rumah Sakit. 2011;111-27.

6. World Health Organisation. Course : Fundamentals in Patient Safety Topic: What is Patient Safety ? World Heal Organ [Internet]. 2012;1-4. Available from: www.who.int/patientsafety/education/cur riculum/course1_handout.pdf.

7. Permenkes No. 25. Manajemen Risiko. 2019;(May):1-9.

8. Adibi $\mathrm{H}$, Khalesi $\mathrm{N}$, Ravaghi $\mathrm{H}$, Jafari $\mathrm{M}$, Jeddian AR. Development of an effective risk management system in a teaching hospital. J Diabetes Metab Disord. 2012;11(1):1-7.
E-ISSN: 2865-6583

P-ISSN: 2865-6298

9. Scott L. Medication errors. Vol. 30, Nursing standard (Royal College of Nursing (Great Britain) : 1987). 2016. 61-62 p.

10. Kemenkes RI. Standar Pelayanan Kefarmasian di Rumah Sakit. Peratur Menteri Kesehat Republik Indones Nomor 58 Tahun 2014 [Internet]. 2014;39(1):115. Available from: http://dx.doi.org/10.1016/j.biochi.2015.03 .025\%0Ahttp://dx.doi.org/10.1038/nature 10402\%0Ahttp://dx.doi.org/10.1038/natur e21059\%0Ahttp://journal.stainkudus.ac.id /index.php/equilibrium/article/view/1268/ 1127\%0Ahttp://dx.doi.org/10.1038/nrmicr o2577\%0Ahttp://

11. Lisby M, Nielsen LP, Mainz J. Errors in the medication process: Frequency, type, and potential clinical consequences. Int J Qual Heal Care. 2005;17(1):15-22.

12. Daud A. Sistem pelaporan dan pembelajaran keselamatan pasien nasional (sp2kpn). 2020;38. 